\title{
Ativação de citocina (fator de necrose tumoral $-\alpha$ ) e resposta clínica induzida pela circulação extracorpórea
}

\author{
Luiz Antônio BRASIL*, Walter José GOMES ${ }^{\star}$, Reinaldo SALOMÃO*, Ênio BUFFOLO* \\ RBCCV 44205-309
}

Brasil L A, Gomes W J, Salomão R, Buffolo E - Ativação de citocina (fator de necrose tumoral - $\alpha$ ) e resposta clínica induzida pela circulaçăo extracorpórea. Rev Bras Cir Cardiovasc 1996; 11 (3): 188-200.

RESUMO: A síndrome de tesposta inflamatória sistêmica induzida pela circulaçăo extracorpórea (CEC) é responsável pela disfunção de órgãos observada em alguns pacientes. O fator de necrose tumoral alfa (TNF $\alpha$ ) tem sido implicado em várias manifestaçóes clínicas no pós-operatório de cirurgia cardiacas com utilização de CEC, principalmente na sindrome vasoplégica. O objetivo deste estudo foi verificar a liberaçắo e os possiveis efeitos do TNFa em pacientes com aterosclerose coronária, submetidos a revascularizaçăo do miocárdio, com ou sem CEC. Foram estudados 20 pacientes, sendo 10 com uso de CEC (Grupo I) $\theta 10$ sem CEC (Grupo II). Amostras sangüineas seriadas foram colhidas durante a intervençăo e até 48 horas após, sendo analisados a presença de TNF $\alpha$ circulante (método imunoenzimático ELISA), contagem de leocócitos e velocidade de hemosedimentaçâo (VHS). Também foram comparados na evoluçāo pósoperatória dos pacientes os parămetros hemodinâmicos (pressão arterial e freqüéncia cardiaca), temperatura, tempo de intubaçăo orotraqueal, sangramento pós-operatório e necessidade de drogas vasoativas. Na análise estatistica foram considerados significativos valores de $p \leqslant 0,05$. No Grupo I, niveis plasmáticos de TNFa (> $10 \mathrm{pg} / \mathrm{ml}$ ) foram detectados em $6(60 \%)$ pacientes. No Grupo II năo ocorreu detecçăo da citocina. Os picos de TNF $\alpha$ ocorreram logo após o ínicio da CEC e foram detectados até 48 horas após. Houve maior predominância no Grupo I em relaçāo ao Grupo II de hipotensāo arterial $(7,4 \pm 1,0$ vs $8,5 \pm 0,67)$, maior necessidade de drogas vasoativas ( 8 vs 1), frequeencia cardiaca mais elevada $(114,2 \pm 8,0$ vs $98 \pm 10 \mathrm{bpm}$ ). maior hipertemia $\left(37,17 \pm 0,54\right.$ vs $\left.36,67 \pm 0,35^{\circ} \mathrm{C}\right)$, maior sangramento pós-operatório $(820 \pm 120 \mathrm{ml}$ vs 360 $\pm 84 \mathrm{~mL}$ ), tempo de intubaçāo orotraqueal mais prolongado $(13,6 \pm 2,2$ vs $9,3 \pm 1,4$ horas) e maior leucocitose. Conciuimos que a CEC induz a liberaçăo de TNF $\alpha$ e predispó $\theta$ a aiteraçōes hemodinâmicas e orgânicas que podem ser deletérias para os pacientes. É possivel que o TNF $\alpha$ esteja envolvido na fisiopatogenia das alteraçōes observadas no presente estudo e a inibiçăo de sua ativação poderia, entăo, contribuir para minimizar estes efeitos.

DESCRITORES: Fator de necrose de tumor, sangue, citocina. Revascularização do miocárdio. Circulaçāo extracorpórea, efeitos adversos. Arteriosclerose coronária.

\section{INTRODUÇÃO}

A circulaçăo extracorpórea é essencial na maioria das cirurgias cardiacas. Lesões teciduais associadas a disfunçōes orgânicas, particularmente no coração e pulmōes, podem ocorrer após a utilização da circulação extracorpórea (CEC) (1).
Cirurgias cardiacas com uso de CEC podem produzir uma resposta inflamatória sistêmica, associada a lesōes orgânicas e aumento da morbidade pós-operatória. Como fatores causais incluímos o trauma cirúrgico, contato do sangue com o circuito extracorpóreo e lesōes de reperfusăo após o término da CEC (2).

Trabalho realizado na Disciplina de Cirurgia Cardiovascular da Escola Paulista de Medicina da Universidade Federai de Sāo Paulo. Såo Paulo, SP, Brasil Apresentado ao $23^{\circ}$ Congresso Nacional de Cirurgia Cardiaca. Recife, PE, 20 a 23 de março 1996.

Da Escola Paulista de Medicina.

Endereço para corresponde̊ncia: Luiz António Brasil. Escola Paulista de Medicina, Disciplina de Cirurgia Cardiovascular. Rua Napoleão de Barros, 715, $3^{\circ}$ andar. Săo Paulo, SP, Brasil. CEP: 04024-002. 
Brasil L A, Gomes W J, Salomão R, Buffolo E - Ativaçāo de citocina (fator de necrose tumoral - $\alpha$ ) e resposta clínica induzida pela circulação extracorpórea. Rev Bras Cir Cardiovasc 1996; 11 (3): 188-200.

O contato do sangue com superfícies năo bioIógicas do circuito extracorpóreo durante a CEC desencadeia a ativaçăo do sistema complemento, de fatores da coagulação, a fibrinólise, a cascata de calicreína e os neutrófilos, com liberação de enzimas proteoliticas e produçăo de radicais livres de $\mathrm{O}_{2}{ }^{(2,3)}$.

O estímulo destes fatores produz uma resposta inflamatória sistêmica referida como "Sindrome Pósperfusāo". Ocorre ativaçāo leucositária e as respostas humoral e celular sistêmicas se manifestam. com presença de leucocitose, aumento da permeabilidade capilar, acúmulo de líquuido intersticial e disfunção de órgăos, ocasionados por lesăo endotelial (2-4).

Clinicamente, a síndrome inflamatória pós. perfusăo se caracteriza pela presença de febre, taquicardia, hipotensăo arterial, coagulopatia, liberaçāo de radicais livres de oxigênio e disfunçōes orgânicas no pós-operatório $(5,6)$.

A ativaçăo do sistema plasmático e celular sangüíneo levando à reação inflamatória sistêmica se assemelha à ativaçāo por endotoxinas, verificada nas sepses gram-negativas (7). Recentes estudos mostraram que as endotoxinas podem estar presentes durante a CEC $(8,9)$

As endotoxinas sāo lipopolissacárides derivados das paredes das bactérias gram-negativas em degradação. Seus efeitos biológicos incluem a ativação do sistema complemento, da cascata da coagulaçăo ou de ambos, sendo um caminho alternativo para a liberação de radicais livres, em resposta à ativaçăo de neutrófilos e aumento da adesividade das células endoteliais (10).

Durante a CEC pode ocorrer vasoconstriçăo esplâcnica, com isquemia da mucosa intestinal $e$, como conseqũência, liberaçăo de endotoxinas na corrente sangüínea, com diminuiçăo de sua eliminação após a CEC, devido à disfunção do sistema reticuloendotelial $(8,10,11)$.

Um quadro atípico de síndrome pós perfusão que guarda estreita relação clínica e hemodinâmica com a sepse foi descrito nos últimos anos e denominado Síndrome Vasoplégica (12). Apresenta resistência vascular sistêmica diminuíaa, com débito cardiaco alto, pressōes de enchimento ventricular baixas, hipotensão e taquicardia.

Recentes estudos revelam que, em resposta às endotoxinas, pode ocorrer liberação de citocinas durante e após a CEC $(13,14)$. As citocinas são polipeptideos endógenos produzidos por uma variedade de células. Elas são mensageiras intercelulares e atuam como um dos principais mediadores das lesōes vasculares e também das disfunçōes orgânicas verificadas na sepse e após a circulação extracorpórea $(10,15)$.
Avanços nas técnicas imunológicas têm permitido medir os componentes plasmáticos e intracelulares destas respostas no pré, trans e pós-operatório. Isto inclui principalmente a ativaçăo do complemento e a sintese de várias citocinas, incluindo o fator de necrose tumoral (TNF $\alpha$ ) e as interleucinas, que servem como marcadores da intensidade do processo inflamatório produzido durante a circulação extracorpórea $(10,15)$.

O TNF $\alpha$ é liberado em resposta às endotoxinas e produtos bacterianos gram-negativos, sendo considerado o principal mediador envolvido na fisiopatologia da sepse produzida por bactérias gramnegativas (16-18). Esta citocina, liberada peios monócitos e macrófagos ativados, é um dos principais fatores envolvidos na fisiopatologia da febre. O TNF $\alpha$ induz febre, taquicardia e hipotensāo arterial $(14,19)$.

A caquexina ou TNF $\alpha$ inclui-se no grupo das citocinas que são glicoproteínas, não imunoglobulinas, liberadas por células vivas do hospedeiro e que agem não enzimaticamente, regulando diversas funçōes celulares (20).

A produçāo do TNF $\alpha$ è feita principalmente pelos macrófagos. Entretanto, outras células produzem TNF $\alpha$, como os linfócitos $T$, mastócitos, células natural "killer", células endoteliais, "mast cells" células de Langerhans, astrócitos, células do músculo liso e células de Kupffer fetal humana (17.21-24).

Vários estímulos, como as endotoxinas, particulas virais, fungos e porção C5a do complemento, săo capazes de provocar a produçāo de TNF $\alpha$ pelos macrófagos, entre estes o LPS é o mais potente $(25,26)$.

Após a induçẵo pelo LPS, o TNF $\alpha$ é repidamente sintetizado, ocorrendo elevaçăo do nível plasmático após 20 minutos, com pico entre 60 min e $90 \mathrm{~min}$, năo sendo mais detectável após 4 horas (19). A meia-vida é curta, de 6 a 9 minutos, e a produçăo de TNF $\alpha$ em resposta ao estímulo com LPS parece ser limitada. Os macrófagos ativados săo capazes de produzir grandes quantidades de proteina por breves períodos de tempo, e pequenas quantidades cronicamente (27).

Säo conhecidos dois receptores especificos para - TNF $\alpha$, sendo um de $55 \mathrm{KDa}$ (TNF-R1) responsável por grande parte da atividade biológica do TNF $\alpha$ (28) e outro de 75KDa (TNF-R2), com função ainda năo esclarecida.

Os receptores para o TNF $\alpha$ estão distribuídos em muitas células como hepáticas, renais, pele e trato gastrintestinal. Eles variam de 200 a 5000 moléculas/célula, e são responsáveis pela rápida eliminação desta molécula da corrente sangüinea (29-31).

Inicialmente, as mensuraçōes do TNF $\alpha$ nos flui- 
Brasil L A, Gomes W J, Salomão R, Buffolo E - Ativaçăo de citocina (fator de necrose tumoral - $\alpha$ ) e resposta clínica induzida pela circulaçāo extracorpórea. Rev Bras Cir Cardiovasc 1996; 11 (3): 188-200.

dos orgânicos foram realizadas através de ensaios de citotoxicidade, pela sua atividade lítica sobre linhagens de células de fibrosarcoma de camundongo (células L929) (32).

Posteriormente, com as limitaçōes deste procedimento, a citocina passou a ser dosada através da marcação com elementos radioativos do anticorpo específico anti-TNF $\alpha$ (radioimunoensaio) (33).

Atualmente, vem sendo utilizado amplamente, pela sua sensibilidade e facilidade de execução, o imunoensaio com enzima ligada ou ELISA, através da ligaçāo de enzimas ao anticorpo anti-TNF $\alpha(33,34)$

As múltiplas atividades biológicas do TNFo determinaram um crescente interesse na avaliaçăo do comportamento dessa citocina, em diversas situaçőes $(33,34)$,

RUS et al. (35), em 1991, estudando cadáveres portadores de doença aterosclerótica, verificaram a presença de TNF $\alpha$ nas paredes das grandes artérias e concluíram que o TNF $\alpha$ em parede arterial aterosclerótica humana poderia ser ativado e envolvido nos eventos inflamatórios associados com aterosclerose.

VADDI et al. (36) (1994) realizaram estudo para investigar a produção de citocinas por leucócitos mononucleares de pacientes com doença cardiaca isquêmica. A secreçăo aumentada de citocina na doença cardíaca isquêmica pode ter papel na geraçāo de radicais livres de oxigênio, lesão endotelial, depósito e ativaçăo de elementos celulares na parede dos vasos e possivelmente na progressāo da aterosclerose.

Recentes estudos $(2,13,14,37)$ têm demonstrado a liberação de citocinas, incluindo o TNF $\alpha$ como fatores que contribuem para o aparecimento da síndrome de resposta inflamatória sistêmica, verificada após cirurgias cardiacas, com o uso de circulaçăo extracorpórea $(5,7,10)$.

\section{OBJETIVO}

O objetivo deste trabalho é estudar a liberação do TNF $\alpha$ e avaliar seus efeitos em pacientes portadores de aterosclerose coronária, submetidos a cirurgia de revascularização do miocárdio, com e sem utilização de circulação extracorpórea.

\section{CASUÍSTICA E MÉTODOS}

No periodo compreendido entre janeiro e junho de 1995,20 pacientes foram selecionados para este estudo, portadores de insuficiência coronária, sub- metidos de maneira consecutiva a cirurgia de revascularizaçăo do miocárdio.

Todos os pacientes foram operados pela equipe cirúrgica da Disciplina de Cirurgia Cardiovascular da Universidade Federal de Săo Paulo - Escola Paulista de Medicina, no Hospital Săo Paulo.

Os pacientes foram divididos em dois grupos:

Grupo I - 10 pacientes operados com uso de circulaçăo extracorpórea.

Grupo II - 10 pacientes operados sem auxílio da circulaçāo extracorpórea.

Os pacientes portadores de diabetes mellitus insulino-dependentes, de doença pulmonar obstrutiva crônica (DPOC), que faziam uso de corticóides ou antiinflamatórios nāo hormonais, e os que já haviam sido submetidos a cirurgia cardíaca prévia, foram excluidos deste estudo.

A técnica anestésica empregada seguiu a rotina do Serviço, com indução através de diazepam (50 mg-Ev), fentanil (50 mcg/ $/ \mathrm{kg})$, hipnomidate $(0,4 \mathrm{mcg} /$ $\mathrm{kg}$ ) e curarizaçāo com pancurônio $(0,1 \mathrm{mg} / \mathrm{kg})$. A anestesia foi mantida com infusão de fentanil, diazepan e inalação de isoflurano. Todos os pacientes foram ventilados com oxigênio a $100 \%$.

A abordagem cirúrgica em todos os pacientes foi através de toracotomia mediana transesternal.

Nos pacientes do Grupo I, a circulaçāo extracorpórea foi instalada com canulação de aorta ascendente e drenagem venosa através de cava única, após heparinizaçāo sistêmica com $4 \mathrm{mg} / \mathrm{kg}$, repetida de acordo com o TCA (tempo de coagulaçăo ativado), com o objetivo de mantê-lo acima de 450 segundos.

$\mathrm{Em}$ todos os casos foi usado oxigenador de membrana (OXIM II-34, MACCHI) acompanhado de reservatório de cardiotomia e filtro de linha arterial, e com tubos das linhas arterial e venosa confeccionados em PVC (cloreto de polivinila). O circuito extracorpóreo foi lavado previamente com solução de Ringer Lactato, desprezada antes da colocação do perfusato.

A composição do perfusato dependeu das condiçōes prévias do paciente, e a hemodiluição total foi empregada, sempre que possivel, com volume de $1500 \mathrm{ml}$ de solução de Ringer Lactato. Acréscimo de sangue, quando necessário, foi feito no sentido de manter o hematócrito entre $26 \%$ e $30 \%$.

Como método de proteção miocárdica foi utilizada cardioplegia sangüínea hipotérmica anterógrada intermitente (a cada 15 minutos), associada a hipotermia sistêmica moderada $\left(29^{\circ} \mathrm{C}\right)$.

Nos pacientes operados sem circulaçăo extra- 
Brasil L A, Gomes W J, Salomão R, Buffolo E - Ativação de citocina (fator de necrose tumoral - $\alpha$ ) e resposta clínica induzida pela circulaçăo extracorpórea. Rev Bras Cir Cardiovasc 1996; 11 (3): 188-200.

corpórea (Grupo II), foi seguida a técnica do Serviço (60), com heparinização sistêmica $(2 \mathrm{mg} / \mathrm{kg}) \mathrm{e}$ uso de Verapamil EV com o objetivo de diminuir a frequêencia cardíaca. Após a dissecção da artéria coronária, esta foi garroteada proximal e distalmente, seguida de sua abertura e realizaçăo da anastomose distal. Posteriormente, dependendo do enxerto, foi realizado pinçamento lateral da aorta ascendente, para feitura da anastomose proximal.

A neutralização da heparina realizada nos dois grupos foi feita com infusāo venosa lenta de sulfato de protamina $(1: 1)$, diluída em soro glicosado a $5 \%$.

Antibioticoterapia profilática foi realizada em todos os pacientes, seguindo normas da Comissāo de Controle de Infecçāo Hospitalar, do Hospital Săo Paulo, com administração de $2 \mathrm{~g}$ de cefazolina EV, uma hora antes da operação e, em seguida, $1 \mathrm{~g} \mathrm{EV}$ 8/8 horas, até o $3^{2}$ dia de pós-operatório.

Terminada a operaçăo, os pacientes em normotemia foram conduzidos à Unidade de Pós-operatório de Cirurgia Cardiaca, com intubação orotraqueal, sendo ventilados através de respiradores volumétricos, com $\mathrm{FiO}_{2}$ necessária para manter a $\mathrm{PaO}_{2}$ acima $100 \mathrm{mmHg}$.

A reposiçăo de volume foi feita através de soluçōes cristalóides acrescidas de eletrólitos, e colóides, se necessário, no sentido de manter bons parâmetros hemodinâmicos, equilibrio hidroeletrolitico e ácido-básico. A taxa de hemoglobina foi corrigida sempre quando esteve abaixo de $9 \mathrm{mg} / \mathrm{dl}$, com reposiçāo de concentrado de glóbulos. Foram prescritos, concomitantemente, nitratos e analgési$\cos$ e manutençăo da antibioticoterapia profilática. Drogas vasoativas e inotrópicas foram usadas se necessário. Năo foram prescritos antiagregantes plaquetários ou quaiquer tipo de antiinflamatório.

Durante a permanência dos pacientes na Unidade de Pós-Operatório (48 horas), foram monitorizados: pressão arterial média, freqüência cardiaca e temperatura axilar, de hora em hora até a extubaçăo orotraqueal $e$, em seguida, de $2 / 2$ horas. Após o registro destes parâmetros, os valores médios foram calculados para cada paciente. Foi também registrado o volume total de sangramento pós-operatório até a retirada dos drenos, e o tempo total de intubação orotraqueal.

Os parâmetros laboratoriais analisados nos dois grupos foram: contagem de leucócitos, velocidade de hemossedimentação (VHS), e dosagem do fator de necrose tumoral alfa (TNF $\alpha$ ), através do ensaio imunoenzimático (ELISA).

Foram colhidas amostras sangüineas seriadas para dosagem destes parâmetros, da artéria radial, e da linha arterial da CEC durante a perfusão, em dois tubos de ensaio ( $5 \mathrm{ml}$ em cada), sendo um tubo enviado prontamente ao laboratório para dosagem dos leucócitos e do VHS. No outro tubo, após centrifugação com 5 RPM a 7000 RPM, durante 10 minutos, foi separado o plasma, dividido em alíquotas de aproximadamente $0,5 \mathrm{ml}$ e estocado em congelador $\left(-70^{\circ} \mathrm{C}\right)$ até a realizaçăo do teste para dosagem do TNF $\alpha$.

O tempo de coleta das amostras foi o seguinte:

\section{Grupo I - Cirurgias com CEC}

Amostra 1 - No início da cirurgia (pré heparinizaçăo e pré CEC)

Amostra 2 - No início da CEC, 10 minutos após - pinçamento aórtico

Amostra 3 - Após despinçamento aórtico e protamina.

Amostra 4 - No final da operação

Amostra 5 - 12 horas de P.O.

Amostra 6 - 24 horas de P.O.

Amostra 7 - 48 horas de P.O.

Grupo II - Cirurgias sem CEC

Amostra 1 - No início da operação (pré heparina)

Amostra 2 - 10 minutos após o garroteamento da coronária

Amostra 3-Após desgarroteamento da coronária e protamina
Amostra 4 - No final da operação
Amostra 5 - 12 horas de P.O.
Amostra 6 - 24 horas de P.O.
Amostra $7 \cdot 48$ horas de P.O.

\section{MÉTODO ESTATÍSTICO}

Para análise dos resultados foram aplicados os testes de Mann-Whitney, a Análise de Variância por postos de Friedman, Teste de Comparaçōes Múltiplas e Teste Exato de Fisher.

Em todos os testes fixou-se em $0,05 \%$ ou $5 \%$ $(\alpha \leqslant 0,05)$ o nivel de rejeição da hipótese de nulidade.

\section{RESULTADOS}

A análise dos grupos quanto ao sexo mostrou, no Grupo I, 6 pacientes do sexo masculino $(60 \%)$ 
Brasil L A, Gomes W J, Salomão R, Buftolo E - Ativação de citocina (fator de necrose tumoral - $\alpha$ ) e resposta clínica induzida pela circulaçāo extracorpórea. Rev Bras Cir Cardiovasc 1996; 11 (3): 188-200.

e 4 do sexo feminino (40\%). No Grupo II houve predomínio do sexo masculino com 7 pacientes $(70 \%)$ e 3 pacientes $(30 \%)$ do sexo feminino.

A idade variou nos dois grupos de 44 anos a 74 anos com média de 64 anos $( \pm 8,2)$ no Grupo I, e média de 63 anos $( \pm 9,3)$ no Grupo II, năo havendo, portanto, diferença significativa entre os grupos.

O peso variou no Grupo I de 50 a $77 \mathrm{~kg}$ (média: $65,3 \pm 10,2)$, e no Grupo II, de $50 \mathrm{~kg}$ a $96 \mathrm{~kg}$ (média: $9,6 \pm 16,2)$. A altura no Grupo I foi 1,50 a $1,75 \mathrm{~m}$ (média: $1,65 \pm 0,09$ ); no Grupo II variou de $1,52 \mathrm{~m}$ a $1,84 \mathrm{~m}$ (média: $1,68 \pm 0,11$ ). Para melhor análise destas duas variáveis (peso e altura) visando à comparaçāo dos grupos, calculamos o indice de massa corpórea (IMC), que se traduz pela divisāo do peso, pela altura em metros ao quadrado $(P /$ $A^{2}$ ), e obtivemos IMC no Grupo I de 23,8; no Grupo II, ele foi de 24,3 , mostrando que naao houve diferença significante, quanto ao IMC, entre os grupos.

Quanto ao número de enxertos (pontes) realizados nos dois grupos, tivemos no Grupo I 1 paciente que recebeu $2(10 \%)$ enxertos, 7 pacientes receberam 3 enxertos $(70 \%)$ e 2 pacientes $4(20 \%)$ enxertos. No Grupo II, pacientes operados sem circulação extracorpórea, tivemos 4 pacientes revascularizados com $1(40 \%)$ enxerto, 2 pacientes com $2(20 \%)$ enxertos e 4 pacientes com $3(40 \%)$ enxertos. Relacionando o número de exertos realizados com e sem circulação extracorpórea com os pacientes operados, encontramos, no Grupo I, média de 3,1 enxertos por paciente e, no Grupo II, 2 enxertos por paciente.

O tempo total de cirurgia variou, no Grupo I, de $260 \mathrm{~min}$ a $360 \mathrm{~min}$, com média de $286,5 \pm 34,5$. Neste grupo em que os pacientes foram operados com utilização de circulaçăo extracorpórea, o tempo total de CEC variou de $85 \mathrm{~min}$ a $160 \mathrm{~min}$, com média de $109 \pm 26,5$, e o tempo de anóxia foi de $55 \mathrm{~min}$ a $112 \mathrm{~min}$ (média: $74 \pm 16$ ). No Grupo II, o tempo cirúrgico fol de $135 \mathrm{~min}$ a $240 \mathrm{~min}$, com média de $195 \pm 35,2$, ocorrendo diferença significativa quanto ao tempo de cirurgia (com CEC > sem CEC).

Com relação à perda sangüínea no pós-operatório, verificou-se uma diferença significativa entre os grupos (com CEC > sem CEC). O total de sangramento no Grupo I variou de $650 \mathrm{ml}$ a 1050 $\mathrm{ml}$ (média: $820 \pm 120$ ) e no Grupo II foi de $250 \mathrm{ml}$ a $500 \mathrm{ml}$ (média: $360 \pm 84$ ) (Gráfico 1).

O tempo total de intubação orotraqueal, demonstrado na Tabela 5, foi no Grupo I, de 10 a 16 horas. (média: $13,6 \pm 2,2)$, e no Grupo II variou de 8 a 12 horas (média: $9,3 \pm 1,4$ ), sendo significante esta diferença (com CEC > sem CEC) (Gráfico 2).
GRÁFICO

TOTAL DE SANGRAMENTO PÓS-OPERATÓRIO

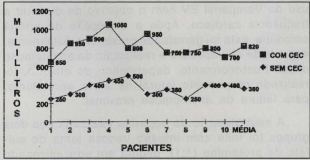

GRÁFICO 2

TEMPO DE INTUBAÇAOO OROTRAQUEAL

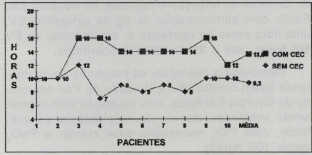

A análise dos valores médios da pressão arterial em $\mathrm{mmHg}$ (PAM), nos dois grupos, revelou no Grupo I uma variação de $6 \mathrm{mmHg}$ a $9 \mathrm{mmHg}$ (média: $7,4 \pm 1$ ), e no Grupo II esta variaçäo ocorreu entre 7 e $9 \mathrm{mmHg}$ (média: $8,5 \pm 0,67$ ), havendo diferença significativa entre os grupos (com CEC < sem CEC) (Gráfico 3).

\section{GRÁFICO 3}

PRESSÄO ARTERIAL MEDIA - VALORES MEDIOS

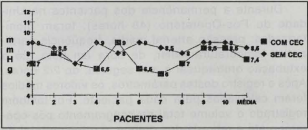

Com relação à freqüência cardiaca observada nos dois grupos, segundo seus valores médios, durante o período de internaçăo dos pacientes na unidade de pós-operatório variou no Grupo I, de 102 bpm a 124 bpm (média: 114,2 \pm 8), enquanto que no Grupo II, esteve entre $84 \mathrm{bpm}$ a $112 \mathrm{bpm}$ (média: $98 \pm 10$ ), havendo diferença significante entre os grupos (com CEC > sem CEC) (Gráfico 4). 
Brasil L A, Gomes W J, Salomão R, Buffolo E - Ativaçăo de citocina (fator de necrose tumoral - $\alpha$ ) e resposta clínica induzida pela circulaçāo extracorpórea. Rev Bras Cir Cardiovasc 1996; 11 (3): 188-200

GRÁFICO 4

FREQÜENCIA CARDIACA - VALORES MÉDIOS

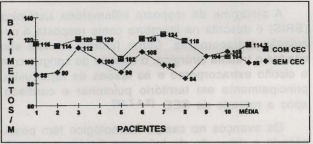

Os valores médios da temperatura, avaliados nos dois grupos, mostraram, no Grupo I, variação entre $36,5^{\circ} \mathrm{C}$ a $37,8^{\circ} \mathrm{C}$ (média: $37,17 \pm 0,54$ ), e no Grupo II, a temperatura esteve entre $36,2^{\circ} \mathrm{C}$ e $37,2^{\circ} \mathrm{C}$ (média: $36,67 \pm 0,35$ ), demonstrando que a temperatura foi significantemente mais elevada no Grupo I, em relaçăo ao Grupo II (Gráfico 5).

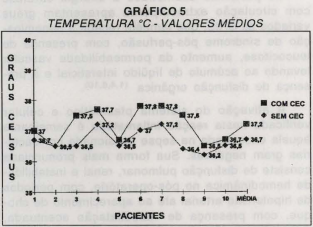

Analisando a contagem dos leucócitos, observamos, após cálculo da média de cada amostra de todos os pacientes em cada tempo, que houve variação significativa entre as amostras colhidas em tempos diferentes, tanto no Grupo I como no Grupo II, com presença de leucocitose nos dois grupos. 0 aumento do número de leucócitos foi mais significativo no Grupo I, com elevaçāo ocorrendo durante a CEC, elevando-se gradualmente $\theta$ atingindo niveis máximos com $24 \mathrm{~h}$ a $48 \mathrm{~h}$ após a operação (Gráfico 6).

A Velocidade de Hemossedimentação (VHS) apresentou nos dois grupos uma diferença significativa em cada amostra, revelando um declínio progressivo após o início da operação e aumento gradual, atingindo valores iguais ou mais elevados que o inicial, após 48 horas. Este fenómeno foi observado em ambos os grupos.
GRÁFICO 6

COMPARACĀO DA LEUCOCITOSE NOS GRUPOS IE I| DE ACORDO COM OS VALORES MEDIOS DE LEUCÓCITOS EM CADA AMOSTRA

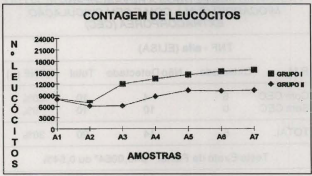

Quando realizada a comparação entre os dois grupos, os niveis só foram significativos nas amostras 2 e 3 , isto é, durante a circulação extracorpórea (com CEC < sem CEC). Nas demais amostras não houve diferença estatisticamente significante entre os dois grupos. Ocorreu uma diminuiçăo significativa do VHS durante a circulação extracorpórea, com aumento gradual nos dois grupos, após a operação, atingindo níveis mais elevados que o inicial, com 48 horas após a cirurgia (Gráfico 7).

\section{GRÁFICO 7}

VARIACCĀO DO VHS COMPARANDO OS VALORES MEDIOS DE CADA AMOSTRA NOS GRUPOS IE II

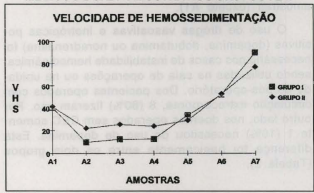

O fator de necrose tumoral alfa (TNF $\alpha$ ) foi detectado somente em paciente do Grupo I. Dos 10 pacientes operados com circulaçăo extracorpórea, em $6(60 \%)$, a citocina foi positiva (Tabela 1).

Os niveis plasmáticos de TNF $\alpha$ variaram de $14,3 \mathrm{pg} / \mathrm{ml}$ a $155,7 \mathrm{pg} / \mathrm{ml}$. Não houve nenhuma detectação na amostra 1 , ou seja, pré-CEC. A detecção de TNF $\alpha$ foi mais freqūente na amostra 2 $(66,6 \%)$, ou seja, durante a CEC, após o pinçamento aórtico. A citocina também foi detectada após a CEC e até 48 horas após a operação (Gráfico 8). 
Brasil L A, Gomes W J. Salomăo R, Buffolo E - Ativaçăo de citocina (fator de necrose tumoral - $\alpha$ ) e resposta clínica induzida pela circulaçāo extracorpórea. Rev Bras Cir Cardiovasc 1996; 11 (3): 188-200.

TABELA 1

PRESENCA OU AUSENNCIA DE TNF- a PLASMÁTICO, EM PACIENTES SUBMETIDOS A REVASCULARIZAÇĀODO MIOCARDIO (R.M.), COM E SEM CIRCULAÇĀO EXTRACORPOREA (CEC)

\begin{tabular}{lcccc}
\hline & \multicolumn{4}{c}{ TNF - alfa (ELISA) } \\
\cline { 2 - 5 } R.M. & Detectado & Năo Detectado & Total & $\%$ TNF (+) \\
\hline Com CEC & 6 & 4 & 10 & $60 \%$ \\
Sem CEC & 0 & 10 & 10 & $0 \%$ \\
\hline TOTAL & 6 & 14 & 20 & $30 \%$ \\
\hline
\end{tabular}

Teste Exato de Fisher - $p=0,0054^{*}$ ou $0,54 \%$

GRÁFICO 8

FREQÜENIA DE DETECCAAO DE TNF EM CADA AMOSTRA

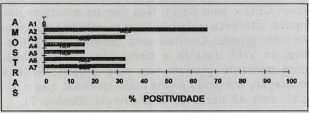

Em 1 paciente, onde o tempo de CEC foi prolongado, a detecçāo de TNF $\alpha$ foi positiva em todas as amostras (exceto A1).

O uso de drogas vasoativas e inotrópicas positivas (dopamina, dobutamina ou noradrenalina) fol necessário nos casos de instabilidade hemodinâmica, sendo utilizadas na sala de operaçōes ou na unidade de pós-operatório. Dos pacientes operados com circulaçăo extracorpórea, $8(80 \%)$ fizeram uso. Por outro lado, nos doentes operados sem CEC somente $1(10 \%)$ necessitou do uso de dopamina. Esta diferença foi basicamente entre os dois grupos (Tabela 2).

TABELA 2

USO DE DROGAS VASOATIVAS EM PACIENTES SUBMETIDOS A AEVASCULARIZACÄO DO MIOCARDIO (R.M.), COM E SEM CIRCULAÇÄO EXTRACORPOREA (CEC)

\begin{tabular}{lcccc}
\hline \multirow{5}{*}{ D.M.Sim } & Nāo & Total & $\%$ Uso drogas \\
\cline { 2 - 5 } Com CEC & 8 & 2 & 10 & $80 \%$ \\
Sem CEC & 1 & 9 & 10 & $10 \%$ \\
\hline TOTAL & 9 & 11 & 20 & $45 \%$ \\
\hline
\end{tabular}

Teste Exato de Fisher -p $=0,0027^{*}$ ou $0,27 \%$

\section{COMENTÁRIOS}

A sindrome da resposta inflamatória sistêmica (SRIS) é descrita na literatura como resposta á circulaçăo extracorpórea. Como fatores causais são citados o trauma cirúrgico, o contato do sangue com - cicuito extracorpóreo e as lesōes de reperfusāo, principalmente em território pulmonar e cardíaco, após a retirada da CEC $(3,4,7,10)$.

Os avanços no campo imunológico tềm possibilitado a detecção de inúmeros fatores responsáveis pela reaçăo humoral e celular que levam ao aparecimento desta síndrome. Estes incluem a ativaçăo do sistema complemento, da coagulaçăo, fibrinólise, da cascata das calicreínas, presença de endotoxinas circulantes, ativaçäo de polimorfonucleares com posterior degradaçāo, causando liberação de enzimas proteolíticas, produção de radicais livres e a síntese de várias citocinas pelos leucócitos polimorfonucleares ativados $(1,6,10)$

Os pacientes submetidos a cirurgia cardíaca com circulaçāo extracorpórea apresentam graus variados da SRIS, que também recebe a denominaçăo de sindrome pós-perfusāo, com presença de leucocitose, aumento da permeabilidade vascular levando ao acúmulo de liquuido intersticial e à presença de disfunção orgânica $(1,4,6,10)$.

A ativação do sistema plasmático e celular verificada nesta reação inflamatória é semelhante àquela encontrada na sepse ocasionada por bactérias gram negativas. Sua forma mais pronunciada consiste de disfunçāo pulmonar, renal e instabilidade hemodinâmica no pós-operatório, com períodos de hipotensão arterial até ao aparecimento de choque, com presença de vasodilatação acentuada necessitando de altas doses de drogas vasoativas (14). Este quadro foi denominado de sindrome vasoplégica e é hoje, em nosso meio, a mais temivel complicação pós-operatória da cirurgia cardíaca com CEC, com mortalidade em torno de $25 \%$ (12)

A ativação do sitema complemento com produçāo de anafilatoxinas (C3a e C5a), após o contato do sangue com a superfície artificial (năo endotelizada) do circuito extracorpóreo, é considerada como um dos principais fatores envolvidos na reaçāo inflamatória $(3,4)$. Niveis de $\mathrm{C} 3 \mathrm{a}$ aumentam rapidamente no início e diminuem no final da CEC, mantendo relação direta com o tempo de CEC, retornando aos valores pré CEC, com 48 horas. Disfunçäo cardiaca e pulmonar, falência renal e tendência ao sangramento têm sido relacionadas com os niveis de $\mathrm{C} 3 \mathrm{a}$ até 3 horas após a perfusāo $(3,10)$. A ativaçăo do complemento, isoladamente, nảo é suficiente para produzir lesōes pulmonares, mas pequenos niveis de $\mathrm{C} 5$ a podem induzir a agregaçāo e marginação de neutrófilos no território pulmonar. 
Recentes estudos demonstraram a presença de endotoxinas durante a circulação extracorpórea $(8,9,39,40)$. Esta poderia ser causada por infusăo venosa de substâncias não estéreis, por utilização de materiais contaminados do circuito extracorpóreo ou instrumental cirúrgico, ou pela ativação do sistema complemento em funçăo do contato do sangue com superfícies não biológicas do circuito extracorpóreo $[7,41)$

A presença de endotoxinas na CEC é também relatada como decorrente da isquemia da mucosa intestinal, relacionada com a duraçăo do pinçamento aórtico ou da própria duração da circulação extracorpórea, onde ocorreria uma exposição dos órgãos a um período mais prolongado de fluxo não pulsátil da CEC, determinando, principalmente, uma vasoconstricção e conseqũente isquemia de órgãos do território esplâncnico. Esta endotoxinemia seria devida à translocaçāo de bactérias gram negativas do intestino, ocasionada por uma possivel quebra de barreira da mucosa intestinal, que em condições normais impede a passagem de componentes tóxicos da luz intestinal para a corrente sangüinea $(7-9,42)$.

Durante os últimos anos, consideráveis progressos têm sido observados no sentido de melhor compreensão dos mecanismos envolvidos nas reaçōes induzidas pelas endotoxinas.

O reconhecimento de que células do sistema reticuloendotelial medeiam a atividade tóxica de endotoxinas, colocou os macrófagos em foco de interesse. Evidências diretas de um papel importante dos macrófagos no desenvolvimento do choque endotóxico têm sido demonstradas através de trabalhos experimentais (43).

Atualmente, está evidente que as atividades biológicas das endotoxinas nāo são diretamente devidas somente aos efeitos do LPS. Esses efeitos são causados indiretamente pela ação de mediadores endógenos produzidos por açāo de endotoxinas (LPS), em locais especificos do organismo $(30,43)$.

Várias citocinas têm sido relatadas como participantes na mediação das reaçōes causadas pelas endotoxinas. Săo produzidas por diferentes tipos de células e funcionam como mensageiros e mediadores de lesões teciduais (44). Uma das mais importantes é o fator de necrose tumoral alfa (TNF $\alpha$ ), uma citocina produzida pelos macrófagos (30).

O TNF $\alpha$ foi descoberto por CARSWELL et al. (45), em 1975, e assim denominado por causar a necrose de alguns tumores. Originalmente o TNF $\alpha$ foi detectado em amostras de camundongos que haviam sido inoculados com o Bacillus Calmette Guérin (BCG) ou Propioniobacterium Acnes, subseqüentemente tratados com LPS.
Hoje o TNFa é reconhecido como um importante mediador da atividade letal das endotoxinas. Sua toxidade direta foi reconhecida inicialmente por BEUTLER et al. $(30,46)$, em 1985, que redescobriram - TNF $\alpha$ como uma substância idêntica à caquexina, um mediador sérico implicado nas síndromes consuntivas, presente nas doenças parasitárias e nas neoplastias. É distinguido do TNF $\beta$ que é uma linfotoxina, por sua diferença estrutural da cadeia polipeptídica e também por seus efeitos.

O TNF $\alpha$ é um dos primeiros mediadores produzidos em resposta ao LPS, sendo sintetizado e liberado pelos macrófagos ativados por endotoxinas. É produzido também pela ativação de monócitos, linfóticitos e células de Kupffer. Dentre os fatores que causam um aumento na sintese de TNF $\alpha$ incluímos a fraçăo C5a do complemento, a interleucina 1 e também as endotoxinas $(10,47)$.

Após o estimulo com LPS, em trabalhos experimentais ${ }^{(30)}$ e também em humanos ${ }^{(19)}$ o TNF $\alpha$ se torna detectável no plasma em aproximadamente 30 minutos, com niveis máximos alcançados entre $60 \mathrm{~min}$ a $90 \mathrm{~min}$, caindo progressivamente e se tornando indetectável após 3 a $4 \mathrm{~h}$.

A fisiopatologia do choque séptico (endotóxico) revela que, nos casos onde ocorre agressão endotelial, lesões por isquemia, as endotoxinas liberadas por bactérias gram negativas levariam a uma síndrome de reação inflamatória sistêmica com proporções variáveis, desde a simples presença de febre acompanhada de leucocitose, até o aparecimento de choque.

Já na síndrome inflamatória pós-perfusão, haveria a ativação do sistema complemento após o contato do sangue com o circuito extracorpóreo ou por ação de endotoxinas, com consequiente liberaçāo de citocinas, dentre elas o TNF $\alpha$, durante ou após a CEC, induzindo sérios danos para o organismo $(7,10)$,

A instabilidade hemodinâmica verificada após a CEC com presença de hipotensão arterial ou ocorrência da síndrome vasoplégica, semelhante ao choque séptico, seria induzida pela ativação do complemento e produçāo de anafilatoxinas (C3a e C5a) ou por ação de endotoxinas, que estimulariam os polimormonucleares e estes liberariam citocinas, as quais seriam responsáveis pela hiporeatividade vascular e vasodilataçăo acentuada, disfunçăo miocárdica e pulmonar, culminando com falência de múltiplos órgāos e sistemas $(7,10)$.

A significância de detecção de citocinas, durante e após a CEC, está relacionada com o grau de lesão tecidual, pois elas funcionariam como marcadores da intensidade da reação inflamatória. É também descrito haver um sinergismo entre os fatores 
Brasil L A, Gomes W J, Salomão R, Buffolo E - Ativaçāo de citocina (fator de necrose tumoral - $\alpha$ ) e resposta clínica induzida pela circulaçäo extracorpórea. Rev Bras Cir Cardiovasc 1996; 11 (3); 188-200.

presentes nesta reação, com acentuação da resposta inflamatória $(1,48)$.

HENNEIN et al ${ }^{(49)}$ demonstraram a relaçāo entre os niveis séricos de TNF $\alpha$, IL-6 e IL-8, com alteração da funçăo ventricular esquerda $e$ isquemia miocárdica, sugerindo que estas citocinas possam ser as causadoras de depressão miocárdica no pósoperatório de pacientes operados com CEC.

A liberaçāo de TNF $\alpha$ resulta no aparecimento de vários efeitos, como febre, leucocitose, hipotensāo arterial, maior necessidade de drogas vasoativas e alteraçōes da barreira endotelial ocasionada pela degradaçāo de neutrófilos, resultando no aumento de líqūido intersticial, levando a alteraçōes da coagulaçăo e comprometimento principalmente da função cardiaca e pulmonar $(7,10,14)$.

É descrito na literatura a presença de TNF $\alpha$ em pacientes portadores de aterosclerose $(35,36)$. Este estudo é inédito em comparar a liberaçāo de TNF $\alpha$ em pacientes portadores de aterosclerose coronária, submetidos à cirurgia de revascularizaçāo do miocárdio, com e sem circulação extracorpórea.

A análise dos dois grupos estudados, em relaçăo ao sexo, revelou predomínio do sexo masculino com $60 \%$ no Grupo I, e $70 \%$ no Grupo II. Com relação às variáveis idade, peso e altura, não houve diferença significativa entre os dois grupos $(p<0,05)$. mostrando serem os dois grupos homogêneos.

O TNF $\alpha$ foi detectado em $6(60 \%)$ pacientes que foram revascularizados com auxilio da circulação extracorpórea. Os níveis plasmáticos de TNF $\alpha$ oscilaram entre $14,3 \mathrm{pg} / \mathrm{ml}$ e $155,7 \mathrm{pg} / \mathrm{ml}$. Näo houve deteç̧äo na amostra 1 , ou seja, antes do início da circulaçäo extracorpórea. A detecçăo de TNF $\alpha$ foi a mais freqüente na amostra $2(66,6 \%)$, durante a circulação extracorpórea, após o pinçamento aórtico, fato este também relatado em outros estudos (7,37.50). Houve detecçăo transitória de TNF $\alpha$ após a CEC no final da cirurgia e também com 12,24 e 48 horas após a cirurgia. Em 1 paciente houve detecção da citocina em todas as amostras (exceto A1), fato este relacionado com tempo de CEC mais prolongada (160 minutos), denotando a ocorrência de reação inflamatória mais acentuada neste paciente.

Nos pacientes operados sem CEC não ocorreu detecção da citocina, sugerindo que a presença de aterosclerose, como demonstrado em outros estudos $(35,36)$, năo é suficiente para causar a liberação de TNF $\alpha(5,48)$

Os pacientes de Grupo I, operados com auxilio da circulação extracorpórea apresentaram diferenças significativas $(p<0,05)$ com relaçăo à pressão arterial, frequência cardiaca, temperatura e também quanto ao uso de drogas vasoativas. Este fato pode estar relacionado com a reaçăo inflamatória pós-perfusão, induzida pela circulação extracorpórea.

Os niveis da pressāo arterial média foram mais baixos neste grupo de doentes, quando comparados com os pacientes do Grupo II, havendo com isso maior necessidade do uso de drogas vasoativas nestes doentes, com a finalidade de melhorar os paråmetros hemodinâmicos. A freqüência cardíaca e a temperatura também apresentaram niveis mais elevados, em comparaçāo com os pacientes operados sem circulaçāo extracorpórea, denotando também a açāo inflamatória.

Com relação à contagem de leucócitos, os dois grupos evoluíram com leucocitose. Houve uma queda nāo significativa do número de leucócitos no início da operação, que pode ter como causa a hemodiluiçäo, e um aumento gradual dos leucócitos que se tornou significante $(p<0,05)$, concomitantemente com a circulaçăo extracorpórea, atingindo níveis máximos com 24 h a 48 h após a operação. Esta leucocitose de origem inflamatória, que se tornou significativa após a liberação do pinçamento aórtico, pode ser devida aos produtos liberados por neutrófilos polimorfonucleares que foram ativados no pulmão $e$ coração durante a parada circulatória. Além disso, - reaquecimento sangûíneo poderia estimular os componentes plasmáticos a reagirem com a superfície não biológica do circuito extracorpóreo, contribuindo também para a leucocitose (14)

O total de sangramento pelos drenos no período de pós-operatório foi mais significativo $(p<0,05)$ nos pacientes operados com circulaçāo extracorpórea. Este fato pode ser decorrente do contato do sangue com superfícies não biológicas do circuito extracorpóreo, ativando o sistema complemento, com produção de anafilatoxinas, principalmente a fraçāo C3a, predispondo maior sangramento pósoperatório (4). O contato do sangue com essa superficie pode também ativar o fator XII, dando início à via intrínseca da coagulação. O fator XIla pode ativar a cascata de calicreínas e esta, ativada, produz bradicinina, causando a vasodilataçăo e au mento da permeabilidade vascular. A fibrinólise é estimulada durante a CEC e os produtos gerados pela degradaçāo do fibrinogênio podem prejudicar a formação de fribrina, a função plaquetária e causar lesão endotelial. A combinaçăo destes efeitos podem levar à lesão capilar, com alteraçōes da hemostasia, determinando maior perda sangũínea $(6,10)$.

O tempo de intubação orotraqueal foi mais prolongado nos pacientes do Grupo I, sendo esta diferença significativa $(p<0,05)$, quando comparada com os pacientes do Grupo II. Os marcadores sistêmicos de resposta inflamatória podem nāo refletir adequadamente eventos intrapulmonares após a CEC. O período de reperfusäo pulmonar é 
crítico, ocorrendo liberação de enzimas e radicais livres pelos neutrófilos em degradação, que foram ativados durante a parada circultória em nivel pulmonar (10). Tem sido demonstrada a presença de TNF $\alpha$ e IL-1 em pacientes com grave comprometimento da funçăo pulmonar, mas os niveis destas citocinas intra-alveolares ainda năo foram investigados após a CEC $(10,51)$.

A velocidade de hemossedimentação apresentou uma queda nos dois grupos no início da operação. Durante a circulação extracorpórea esta queda fol significante $(p<0,05)$ nos pacientes do Grupo I. Após a cirurgia, os dois grupos apresentaram aumento progressivo do VHS, atingindo niveis mais elevados que o inicial com $24 \mathrm{~h}$ a $48 \mathrm{~h}$ após a cirurgia, sem significado estatístico, retornando aos niveis do período pré-operatório em torno do $7^{2}$ dia de pós-operatório.

O reconhecimento de que as citocinas agem como mediadores da intensidade da reação inflamatória, induzida pela circulação extracorpórea, fez com que vários autores investigassem formas para atenuar e, mesmo, suprimir estes efeitos.

MARKEWITZ et al. (52) demonstraram que o uso de indometacina e timopentina podem suprimir a liberação de citocinas após a CEC. Outros investigadores preconizaram a descontaminação seletiva do tracto gastrintestinal com o objetivo de reduzir a endotoxinemia durante $\theta$ após a CEC, com a resultante diminuiçăo da produção de citocinas, ativaçăo do complemento e subseqüente diminuiçảo da resposta inflamatória (42),

O uso de corticosteroides também tem sido demonstrado ser eficaz ${ }^{(14,41,53,54)}$ visando diminuir os efeitos sitêmicos induzidos pela liberação de citocinas durante $e$ após a CEC. A pentoxifilina tem sido preconizada por alguns autores $(58,59)$, na prevenção e inibição das ações das citocinas.

$O$ emprego de hemofiltros durante a CEC foi relatado na literatura, com o objetivo de retirar as citocinas da circulação, visando a diminuição da resposta inflamatória após a CEC $(55,56)$.

Outros autores $(6,57)$, com a finalidade de reduZir a ativaçăo dos componentes sangüineos através do contato do sangue com superfícies não biológicas do circuito extracorpóreo, demonstraram que a utilizaçấo de circuitos revestidos com heparina resulta na diminuição da ativação de mediadores responsáveis pela reação inflamatória sistêmica.

Avanços nessa área serão obtidos através de estudos prospectivos que permitam conhecer com maior profundidade a interação entre os mediadores das respostas humoral e celular, induzidas pela circulaçăo extracorpórea, possibilitando também intervenções mais eficazes, no sentido de inibir os efeitos deletérios e reduzir a morbidade de pacientes submetidos à cirurgia cardiaca com o uso de circulaçăo extracorpórea. Abre também a perspectiva de pesquisa de inibidores eficazes que possam contribuir para minorar os efeitos sistêmicos do uso da circulação extracorpórea.

\section{CONCLUSÖES}

1) A circulação extracorpórea induz a liberaçăo do fator de necrose tumoral alfa (TNF $\alpha$ ), e predispōe a alteraçōes hemodinâmicas e orgânicas que podem ser deletérias para os pacientes.

2) Como o TNF $\alpha$ é capaz de induzir alterações hemodinâmicas e orgânicas, sugerimos que - mesmo desempenha importante papel na fisipatogenia das alteraçōes observadas neste estudo.

3) O bloqueio da ativação e produção de citocinas pode contribuir para minimizar essas alteraçōes. 
Brasil L A, Gomes W J, Salomão R, Buffolo E - Ativação de citocina (fator de necrose tumoral - $\alpha$ ) e resposta clinica induzida pela circulaçāo extracorpórea. Rev Bras Cir Cardiovasc 1996; 11 (3): 188-200.

\section{RBCCV $44205-309$}

Brasil L A, Gomes W J, Salomāo R, Butfolo E - Cytokine activation (tumor necrosis factor - $\alpha$ ) and clinical response induced by cardiopulmonary bypass. Rev Bras Cir Cardiovasc 1996; 11 (3): 188-200.

ABSTRACT: Systemic inflammatory response syndrome induced by cardiopuimonary bypass (CPB) is responsible for organ dysfunctions observed in some patients. The tumor necrosis factor-alpha (TNF- $\alpha$ ) has been implicated in many clinical manifostation following cardiac operations with CPB, mainly in the vasoplegic syndrome. The purpose of this study was to verify the TNF- $\alpha$ release and its possible effects in patients with coronary atherosclerosis undergoing coronary artery surgery with and without CPB. Twenty patients were studied, 10 with $\mathrm{CPB}$ (Group I) and 10 without CPB(Group II). Serial blood samples were obtained during and until 48 hours after surgery in order to measure circulating TNF- $\alpha$ presence (using enzyme-linked immunosorbent assay-ELISA), leukocyte count and erythrocytes sedimentation rate. Hemodynamic parameters as blood pressure and cardiac rate, body temperature, orotracheal tubing time, postoperative bleeding and inotropic drugs requirements were also compared. Statistical significance was assumed when the $p$ value was less than 0.05 . Serum levels of TNF- $\alpha$ (limit detection of the assay $=10 \mathrm{pg} / \mathrm{mL}$ ) were detected in 6 patients from Group I $(60 \%)$. This cytokine was detected in Group II. The TNF- $\alpha$ peaked soon after the CPB starting and remained detectable 48 hours postoperatively. The patients of Group I had hypotension in relation to Group II $(7.4 \pm 1.0$ vs $8.5 \pm 0.67)$. They also required more inotropic drugs ( $8 \mathrm{vs} 1)$, had a higher cardiac rate ( 114.2 \pm 8.0 vs $98 \pm 10 \mathrm{bpm})$, hyperthermia $\left(37.17 \pm 0.54 \mathrm{vs} 36.67 \pm 0.35^{\circ} \mathrm{C}\right)$, more postoperative bleeding $(820 \pm 120$ $\mathrm{mL}$ vs $360 \pm 84 \mathrm{~mL}$ ), a longer orotracheal tubing time (13.6 $\pm 2.2 \mathrm{vs} 9.3 \pm 1,4$ horas) and a more pronounced leucocytosis. We concluded that CPB induces the TNF $\alpha$ release and leads hemodynamic and organic alterations that can be deleterious to patients. It may play a role on the pathophysiology of the alterations observed in this study and the inhibition of the TNF $\alpha$ could contribute to minimize these effects.

DESCRIPTORS: Tumor necrosis factor, blood, cytokine. Myocardial revascularization. Extracorporeal circulation, adverse effects.

\section{REFERÊNCIAS BIBLIOGRÁFICAS}

1 Westaby S - Organ dysfunction after cardiopulmonary bypass: a systemic inflammatory reaction by the extracorporeal circuit. Intensive Care Med 1987; 13: 89.5.

2 Butler J, Chong G L, Baigrie R J, Pillai R, Westaby S, Rocher G M - Cytokine response to cardiopulmonary bypass with membrane and bubble oxygenation. Ann Thorac Surg 1992; 53: 833-8.

3 Chenoweth D E, Cooper S W, Hugli T E, Stewart R W, Blackstone E H, Kirklin J W - Complement activation during cardiopulmonary bypass: evidence for generation of $\mathrm{C} 3 \mathrm{a}$ and $\mathrm{C5a}$ anaphylatoxis. N Engl J Med 1981; 304: 497-503.

4 Kirklin J K, Westaby S, Blackstone E H, Kirklin J W, Chenoweth DE. Pacifico A D - Complement and the damaging effcts of cardiopulmonary bypass. $J$ Thorac Cardiovasc Surg 1983; 86: 845-57.

5 Casey L C - Role of cytokines in the pathogenesis of cardiopulmonary-induced multisystem organ failure. Ann Thorac Surg 1993; 56: 92-6.

6 Steinberg B, Grossi E A, Scwartz D S et al. - Heparin bonding of bypass circuits reduces cytokine release during cardiopumonary bypass. Ann Thorac Surg 1995; 60 : 525-9.
7 Jansen $\mathrm{N} \mathrm{J}$, Van Oeveren W, Gu $Y \mathrm{~J}$, Van Vliet $\mathrm{M} \mathrm{H}$ Eijsman L, Wildevuur C R - Endotoxin release and tumor necrosis factor formation during cardiopulmonary bypass. Ann Thorac Surg 1992; 54: 744-8.

8 Andersen $L$ W, Baek L, Degn $H$, Lehd J, Krasnik $M$, Rasmussen S P. Presence of circulating endotoxins during cardiac operations. I Thorac Cardiovasc Surg 1987; 93: 115-9.

9 Rocke D A, Gaffin S L, Wells M T, Koen Y, Brock-Utine $J$ G - Endotoxemia associated with cardiopulmonary bypass. J Thorac Cardiovasc Surg 1987: 93: 832-7.

10 Butler J, Rocher G M, Westaby S - Inflammatory response to cardiopulmonary bypass. Ann Thorac Surg 1993; 55: 552-9.

11 Andersen L W, Landow L, Jansen E, Barker S . Association between gastric intramucosal $\mathrm{pH}$ and splanchnic endotoxin, antibody to endotoxin, and tumor necrosis factor-alpha concentrations in patients undergoing cardiopulmonary bypass. Crit Care Med 1993:21:210-7

12 Gomes W J, Carvalho A C, Palma J H, Gonçalves Jr. 1. Buffolo E - Vasoplegia syndorme: a new dilemma. $\checkmark$ Thorac Cardiovasc Surg 1994; 107: 942-3.

13 Haeffner-Cavailion N, Rousselier N, Ponzio O - Induction of interleukin-1 production in patients undergoing cardiopulmonary bypass. J Thorac Cardiovasc Surg 1989; $98: 1100-6$. 
Brasil L A, Gomes W J, Salomăo R, Buffolo E - Ativação de citocina (fator de necrose tumoral - $\alpha$ ) e resposta clínica induzida pela circulaçāo extracorpórea. Rev Bras Cir Cardiovasc 1996;11 (3): 188-200.

14 Jansen N J, Van Oeveren W, Van Der Broek L et al. Inhibition by dexamethasone of the reperfusion phenomena in cardiopulmonary bypass. $J$ Thorac Cardiovasc Surg 1991; 102:515-25.

15 Moat N E, Shore D F, Evans T W - Organ dysfcunction and cardiopulmonary bypass: the role of complement and complement regulatory proteins. Eur $J$ Cardiothorac Surg 1993; 7: 563-73.

16 Beutler B \& Cerami A - Cachetin: more than a tumor necrosis factor. N Engl J Med 1987; 316: 379-85.

17 Beutler B \& Cerami A - The common mediator of shock cachexia and tumor necrosis. Adv Immunol 1988; 42: 213-31.

18 Tracey $\mathrm{K} \mathrm{J}$, Fong $\mathrm{Y}$, Hesse D G et al. - Anti-cachetin / TNF monoclonal antibodies prevent septic shock during lethal bacteraemia. Nature 1987; 330:682-4

19 Michie H R, Manogue KR, Spriggs D R et al, - Detection of circulating tumor necrosis factor after endotoxin administration. N Engl J Med 1988: 318: 1481-6.

20 Nathan C \& Sporn M - Cytokines in context. J Cell Biol 1991; 113: $981-6$.

21 Beutler B \& Cerami A - Tumor necrosis, cachexia, shock and inflammation: a common mediator. Ann Rev Biochem 1988; 57: 505-18.

Beutler B - TNF in pathophysiology: biosynthetic regulation. J Invest Dermat 1990; 95 (Suppl.): 81-4.

23 Beutler B - The tumor necrosis factors: cachetin and lymphotoxin. Hosp Pract 1990; 15: 45-58.

24 Kutteh W H, Rainey W E, Beutler B, Carr B R - Tumor necrosis factor-alpha and interleukin-1 beta production by human fetal kupffer cell. Am J Obstet Gynecol 1991; 165: 112-20.

25 Dieu J Y, Blanchard D K, Richards A L, Friedman H Tumor necrosis factor induction by Candida albicans from human natural killer cells and monocytes. $J$ Immunol 1988; 141: 4047-52.

26 Tracey K J, Vlassara H, Cerami A - Cachetin/tumo necrosis factor. Lancet 1989; 1: 1122-6.

27 Waage A, Halstensen A, Espevik T - Association between tumor necrosis factor and fatal outcome in patients with meningococcal disease. Lancet 1987; 14: 355-7.

28 Rothe J, Lesslauer W, Lotsher $\mathrm{H}$ et al. - Mice lacking the tumor necrosis factor receptor 1 are resistant to TNF-mediated toxicity but highly susceptible to infection by Listeria monocytogenes. Nature 1993; 364: 798-802.

Aggarwal B B, Kohr B J, Hass P E et al. - Human tumor necrosis factor production, purification and characterization. J Biol Chem 1985; 260: 2345-54.
30 Beutler B, Milsark I W, Cerami A - Cachetin/Tumor necrosis factor: production, distribution and metabolic fate in vivo. $J$ Immunol 1985; 135: 3972-7.

31 Staubep G B, Aiyer R A, Aggarwall B B - Human tumor necrosis factor-alpha receptor: purification by immunoaffinity chromatografhy and initial characterization. J Biol Chem 1988; 263: 19098-104.

32 Flick D A \& Gifford G E - Comparison of in vitro cell cytotoxic assays for tumor necrosis factor. $J$ Immunol Methods $1984 ; 68: 167-75$.

33 Santos B F C - Produçăo do fator de necrose de tumor por leucócitos mononucleares humanos [Tese. Mestrado] Săo Paulo: Escola Paulista de Medicina da Universidade Federal de São Paulo, 1992. 65p

34 Karhawi A S K - Avaliaçāo dos niveis plasmáticos de fator de necrose tumoral-alpha (TNF-alpha), interleucina-6 (IL-6) e contagem de linfócitos-T CD4+ - CD8 + em pacientes com paracoccidioidomicose [ Tese. Mestrado] São Paulo: Escola Paulista de Medicina da Universidade Federal de São Paulo, 1994. 123p.

35 Rus H G, Niculescu F, Vlaicu R - Tumor necrosis factoralpha in human arterial wall with atherosclerosis. Atherosclerosis 1993: 89: 247-54.

Vaddi K, Nicolini F A, Metha P, Metha J L - Increased secretion of tumor necrosis factor-alpha and interferon gama by mononuclear leukocytes in patients with ischemic heart disease. Circulation 1994; 90: 694-9.

Casey W F, Hauser G J, Hanrallah A S, Midgley F M, Khan W N - Circulating endotoxin and tumor necrosis factor during pediatric cardiac surgery. Crit Care Med 1992; 20: 1090-6.

38 Holzheimer A G, Molloy R G, Gorlach H, Wilkert S, Herlein F - IL6 and TNF-alpha release in association with neutrophil activation after cardiopulmonary bypass surger. Infection 1994; 22: 37-42.

39 Kharazmi A, Andersen L W, Baek L, Valerius N H, Laub $M$, Rasmussen J P . Endotoxemia and enhanced generation of oxygen radicals by neuthophils from patients undergoing cardiopulmonary bypass. $J$ Thorac Cardiovasc Surg 1989; 98: 381-5.

40 Nilsson L, Kulander L, Nystrom S O, Eriksson O. Endotoxins in cardiopulmonary bypass. $J$ Thorac Cardiovase Surg 1990; 100: 777-80.

41 Andersen L W, Baek L, Thomsen B S - Effect of methylprednisolone on endotoxaemia and complement activation during cardiac surgery. $J$ Cardiothorac Anesth 1989; 3: 544-9.

42 Martinez-Pellus A E, Merino P, Bru M, et al. - Can selective digestive decontamination avoid the endotoxemia and cytokine activation promoted by cardiopuimonary bypass? Crit Care Med 1993; 21: 1684-91. 
Brasil L A, Gomes W J, Salomão R, Buffolo E-Ativação de citocina (fator de necrose tumoral - $\alpha$ ) e resposta clínica induzida pela circulaçāo extracorpórea. Rev Bras Cir Cardiovasc 1996; 11 (3): 188-200.

Beutler B, Mahoney J, Trang N L, Pekala P, Cerami A - Purification of cachectin a lipoprotein lipase. supressing hormone secreted by endotoxin-induced RAW 264.7 cells. J Exp Med 1985; 161: 984-95.

Fong $Y$, Moldawer L L, Shires G T, Lowry S F - The biologic characteristics of cytokines and their implications in surgical injury. Surg Gynecol Obstet 1990; 170: 363-78.

45

Carswell E A, Old L J, Kassel R L, Green S, Fiore N, Williamson B - An endotoxin-induced serum factor that causes necrosis of tumors. Proc Natl Acad Sct USA $1975 ; 72: 3666-70$

Beutler B, Milsark I W, Cerami A - Passive immunization against cachetin / tumor necrosis factor protects mice from lethal effect of endotoxin. Science 1985; 229: 869-71.

47 Okusawa S, Yancey K B, Van Der Meer J W M - C5a stimulates secretion of tumor necrosis factor form human mononuclear cells in vitro: comparison with secretion of interleukin-1 beta and interleukin-1 alfa. $J$ Exp Med 1988; 168: 443-8.

Casey L C, Balk R A, Bone R C - Plasma cytokine and endotoxin levels correlate with survival in patients with the sepsis syndrome. Ann Intern Med 1993; 119: 771-8.

Hennein H A, Ebba H, Rodriguez J L et al. - Relationship of the proinflammatory cytokines to myocardial ischemia and dysfunction after uncomplicated coronary revascularization. J Thorac cardiovasc Surg 1994; 108: 626-35.

50. Lahat N, Zlotnick A Y, Shtiller R, Bar I, Merin G - Serum levels of IL-1, IL-6 and tumor necrosis factors in patients undergoing coronary artery bypass grafts or cholecystectomy. Clin Exp immunol 1992; 89: 255 60.

51 Millar A B, Foley N M, Singer M, Johnson N M, Meager A, Rook G A W - Tumor necrosis factor in bronchopulmonary secretions of patients with adult respiratory distress syndrome. Lancet 1989; 2: 712-4.
52 Markewitz A, Faist E, Lang S, Endres S, Hultner L, Reichart B - Regulation of acute phase response after cardiopulmonary bypass by immunomodulation. Ann Thorac Surg 1993; 55: 389-94.

53 Hill $G$ E, Alonso $E$, Thiele G M, Robbins R A. Glucocorticoids blunt neutrophil CD11b surface glycoprotein impregnation during cardiopulmonary bypass in humans. Anesth Analg 1994; 79: 23-7.

54 Inaba H, Kochi A, Yorozu S - Suppression by methylprednisolone of augmented plasma endotoxinlike activity and interleukin- 6 during cardiopulmonary bypass. Br $J$ Anaesth 1994; 72: 348-50.

55 Journois D, Pouard P, Greeley W J, Mauriat P, Vouhe $P$. Safran D - Hemofiltration during cardiopulmonary bypass in pediatric cardiac surgery. Effects on hemostasis, cytokines and complement components. Anesthesiology 1994; 81: 1181-9.

56 Millar A B, Armstrong L, Van Der Linden J et al. - Cytokine production and hemofiltration in children undergoing cardiopulmanary bypass. Ann Thorac Surg 1993 56: $1499-502$.

57 Gu Y J, Van Oeveren W, Akkerman C, Boonstra P W, Huyzen R J, Wildevuur C R - Heparin-coated circuits reduce the inflamatory response to cardiopulmonary bypass. J Thorac Cardiovasc Surg 1993; 105: 234 41.

58 Lilly C M, Sandhu J S, Ishizaka A - Pentoxifylline prevents tumor necrosis factor-induced lung injury. Am Rev Respir Dis 1989; 139: 1361-8.

59 Sullivan G W, Carper H T, Novick W J, Mandell G L. Inhibition of the inflamatory action of interleukin-1 and tumor necrosis factor (alpha) on neutrophil function by pentoxifyline. Infect Immunol 1988; 56: $1722-9$.

60 Buffolo E, Gomes W J, Andrade J C S et al. Revascularizaçâo miocárdica sem circulaçăo extracorpórea: resultados cirúrgicos em 1090 pacientes. Arq Bras Cardiol 1994; 62: 149-53. 